\title{
How could disclosing incidental information from whole-genome sequencing affect patient behavior?
}

In this article, we argue that disclosure of incidental findings from whole-genome sequencing has the potential to motivate individuals to change health behaviors through psychological mechanisms that differ from typical risk assessment interventions. Their ability to do so, however, is likely to be highly contingent upon the nature of the incidental findings and how they are disclosed, the context of the disclosure and the characteristics of the patient. Moreover, clinicians need to be aware that behavioral responses may occur in unanticipated ways. This article argues for commentators and policy makers to take a cautious but optimistic perspective while empirical evidence is collected through ongoing research involving whole-genome sequencing and the disclosure of incidental information.

\section{KEYWORDS: contextual factor health behavior incidental finding whole-genome sequencing}

Whole-genome sequencing (WGS) is an increasingly valuable tool for diagnosing disease and optimizing treatments $[1,2]$. Its use also raises difficult questions regarding what to do with the vast amounts of information generated that is incidental to the original purposes of sequencing, but have implications for health and wellbeing. The question of how physicians should handle these incidental findings (IFs) has been the topic of much discussion. While guidance has been sought from existing literature [3,4], WGS differs from technologies such as imaging on several key aspects. Unlike tools such as imaging, which may generate information of uncertain significance, WGS is guaranteed to generate IFs with variable clinical utility, with implications for personal disease susceptibility, risks to offspring and pharmacological implications. Moreover, the IFs generated generally have strong implications for blood relatives. Among the uncertain implications of disclosing WGS IFs are how they might change health behaviors.

The ability of genetic information of any kind to motivate individuals to make sustained lifestyle modifications to reduce their risks of disease has been questioned. Genetic testing for rare, highly penetrant mutations, such as $B R C A 1 / 2$ testing for hereditary breast and ovarian cancer syndromes, and Lynch syndrome testing for colorectal cancer risk, showed that testing could motivate adherence to screening recommendations [5]. Early work on the behavioral impact of genetic susceptibility testing for a common disease using a marker of far less predictive value, $A P O E$ genotyping to determine
Alzheimer's disease (AD) risk, also showed promising results. Individuals in the REVEAL Study who learned that they were at increased genetic risk for developing $\mathrm{AD}$ in the future were not only more likely to report modifying potential risk-reducing behaviors compared with those who learned that they did not have an increased genetic risk or did not receive a genetic risk of assessment [6], but also were more likely to report changing their long-term care insurance coverage [7]. The preponderance of studies examining the behavioral impact of genetic susceptibility testing using markers of moderate-to-low predictive power has been far less encouraging, however. Genetic testing for lung cancer susceptibility has shown the ability to motivate smoking cessation over short periods at best [8] and nearly all other studies have shown no impact of testing on lifestyles such as diet and exercise [5,9]. Such work has led many to question the ability of genetic information to be an effective public health tool for motivating lifestyle modifications to reduce disease risk [10].

However, reasons exist to think the disclosure of IFs during WGS might be different. In a randomized trial involving $A P O E$ genotyping to determine susceptibility to $\mathrm{AD}$, preliminary analyses showed that participants who learned of an additional association between $A P O E$ and heart disease were more likely to report changes to a variety of health behaviors, including diet, exercise, stress management and vitamin usage at follow-up [11]. Furthermore, emotional responses were no worse and possibly better, among those who were disclosed the IFs [12]. While these

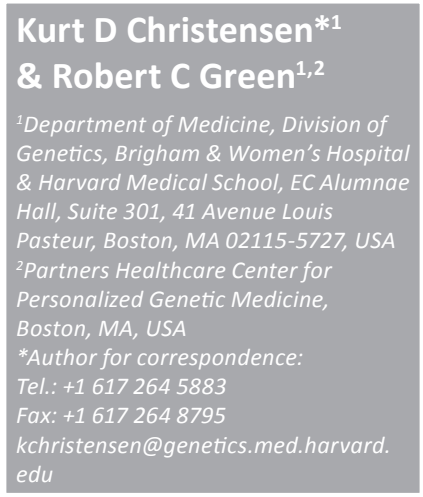

Future
Medicine $\mathrm{fS}$ 
findings need to be both confirmed and replicated, they represent promising initial evidence that disclosure of IFs from genetic analyses can have beneficial effects.

The article that follows speculates on the potential health behavior effects of disclosing IFs more generally from WGS, with a focus on lifestyle modifications made in response to WGS conducted for clinical purposes (e.g., as opposed to research findings). First, we briefly summarize the literature on health behavior change following genetic risk disclosure and address theoretical considerations of the potential for IF disclosure to motivate it. We then discuss how aspects of the IFs, the context of disclosure and patient-specific factors affect the likelihood of behavior change. Finally, we look ahead to potential developments in the field, speculating on how they will affect attitudes towards IFs and patients' responses to them. While the term, 'incidental findings', has been used in many different ways in the literature, we refer to it here in its most general definition: information that is 'unrelated to reasons for ordering' [13].

\section{Health behavior responses to genetic risk assessments \& the disclosure of unexpected information}

Studies that examine the impact of risk information, genetic or otherwise, have long attempted to motivate individuals to make health behavior changes using planned, stepwise programs that communicate individuals' susceptibility to disease, while emphasizing the ability of lifestyle modifications to reduce those risks. Consistently, behavior change following such interventions has been minimal. Over 25 years ago, Becker and Janz concluded, "The provision of typical [health risk appraisal] feedback should not (on a theoretical basis) ordinarily be expected to accomplish much beyond information transmission, belief or attitude change, and the induction of some level of motivation" [14].

Interestingly, a more successful foundation for lifestyle change may be created by significant and unanticipated events. Events such as a heart attack of a loved one or a lung cancer diagnosis of a relative can spur individuals into action [15]; and work on addictive behaviors such as smoking and drinking have shown that such events can be more successful at motivating lifestyle modifications than well-planned interventions [16]. Moreover, changes following unplanned changes are often more sustained than planned changes [17,18]. It is believed that such events cause individuals to have powerful epiphanies. Some experts have embraced the idea of steering individuals into 'mini-epiphanies' as a way of initiating health behavior changes [19].

The ability of IFs from WGS to motivate behavior change through either rational, deliberative processes or through epiphanies is likely contingent upon many factors, however. In the next section, we focus on characteristics of the IFs, the context of disclosure, and patientspecific factors as important enabling factors for health behavior change.

\section{Characteristics of the information \& how it is communicated}

Near consensus exists that incidental genetic information should be disclosed if it involves substantial risk of a preventable or treatable condition, when the information has been analytically and clinically validated, and when individuals have been forewarned that they may be informed about IFs [20]. The preponderance of incidental information fails to meet these criteria and clinicians are required to use their best judgment to determine what to disclose. Not surprisingly, consensus on what merits disclosure is weak among physicians, genetic counselors and laboratories $[13,21]$. To complicate the issue, clinical utility might not be the only criteria to judge what is worthy of disclosure. While some clinicians argue that only incidental results of clear clinical utility should be shared with individuals [22], others argue that clinicians have an obligation to disclose information that has meaning to patients [23], while still others have suggested that patient preferences, established prior to the sequencing, might help determine what to disclose [24,25]. Each of these approaches has substantial implications for the type and amount of incidental disease information that individuals learn.

The likelihood that IFs will motivate individuals to change health behaviors will be contingent upon the type of information that would be disclosed. In particular, WGS can generate disease susceptibility information of variable predictive power. The kinds of IFs that are most likely to be disclosed in the near future are rare variants that are highly penetrant rather than common variants associated with small increases in risk and are therefore more likely to motivate behavior changes [26]. However, risk perceptions can be surprisingly resistant to change $[27,28]$ and even when genetic information alters them, the effect is frequently transient for even highly penetrant mutations [29]. In fact, the ability of genetic risk information to change other disease beliefs, such as the perception 
that a condition is controllable, have been unimpressive, with most analyses showing no effects at all [30]. Moreover, how other types of WGS IFs change patient health behaviors is almost entirely speculative. Pharmacogenomic information has the potential to alter the way patients approach both prescription and over-the-counter medications, and carrier information on conditions with autosomal or X-linked recessive patterns of inheritance may affect mating choices and reproductive decisions. Data on how these types of information, disclosed when they weren't solicited in the first place, change patient behaviors is currently lacking.

The quantity of information disclosed is also likely to affect how people respond to the disclosure of IFs. The number of IFs any given individual will have that indicate a substantial risk of a modifiable condition has been estimated to be three to five by some [31], or to number in the tens by others [24]. Whatever the actual number is, it will clearly be far less than all other types of IFs, which number in the thousands to tens of thousands [31]. As mentioned before, consensus is lacking on what should be disclosed and some argue that disclosure should be driven by patient preferences. Of note, regarding the latter suggestion is that the evidence garnered to date suggests that participants want as much information as possible $[32,33]$. The implications for health behaviors are significant: disclosing copious amounts of incidental information has the potential to overwhelm individuals and inhibit their ability to act on the information, thus decreasing the likelihood that behavior change will ensue. Compounding the complexity, genetic test providers often adopt a 'more-ismore' approach to presenting risk information. Addressing too many issues simultaneously or increasing the amount of information provided during risk communication appears to compromise recall and comprehension [34,35]. One explanation provided for the apparent lower uptake of cholesterol screening following tailored risk assessment based on family history, for instance, was that messages embedded in the 8-15-page tailored report issued to the intervention arm were too complex relative to a 1-page directive message given to control arm participants [36]. If those communicating IFs from WGS to patients hope to use them to motivate behavior change, they will need to be judicious about what to disclose and what to omit.

Another challenge to any type of health communication intervention is maximizing the relevance of the information. People are more likely to process information deeply and be persuaded by information that is consistent with existing beliefs and attitudes than information in conflict with them [37]. Processes such as weighing the pros and cons of behavior change have actually been associated with lower rates of behavior change in instances where particular health communications and individuals' lifestyles and beliefs were in conflict, causing 'reactance' to occur where individuals do not simply ignore the message, but reject it altogether [38,39]. In the context of genetic risk assessments, this danger may be especially high. Nearly all studies of genetic susceptibility testing to date have attempted to convince individuals with strong beliefs about the genetic basis for disease (e.g., by seeking to participate in genetic susceptibility testing research) that they should focus on behavioral factors instead and change their lifestyles. While individuals do not interpret genetic information for modifiable conditions deterministically [30], some evidence suggests that individuals at increased genetic risk of disease may favor biologically based responses (e.g., medications) over lifestyle modifications [40].

Yet, genetic information is well suited to feel personally meaningful to individuals. People tend to think about DNA as units of family identity [41] and genetics has embedded itself in everyday culture and conversation in ways that have powerful positive meanings (e.g., when leaders talk about the "DNA of their businesses" [42]). In addition, the burgeoning research on consumer genetic testing shows that services that profile the geographic ancestry of individuals based on mitochondrial DNA profiles or specific SNP patterns rival health-specific motivations as drivers for the uptake of services [43]. If the ability of IFs to motivate behavior change is dependent upon their ability to create a kind of epiphany and if the ability of an epiphany to occur is dependent upon people's ability to connect with information, then it is worth noting that genetic information can have greater personal meaning to individuals than other types of risk information.

The preceding points suggest that communicating genetic risk information to promote health behavior changes might require a more nuanced approach than is typically used. To minimize the potential for reactive responses, some experts recommend that health educators avoid telling people that their existing beliefs and attitudes need to change, but to 'roll with resistance' [44] and acknowledge them without judgment. It has been suggested that disease 
representations often overlap with conceptions of the self [45]. Affirmation of the self may be one of the strongest motivators of behavior [46] and providing it appears to make people more receptive to persuasive messages [47]. For the purposes of using WGS IFs to motivate behavior change, this might mean spending more time addressing the meaning of genetics and family history after a risk assessment, and delaying the typical reflex among physicians and health educators to tell a person to mitigate their inherited risks through lifestyle modification. Such ideas have been proposed in the past $[45,48]$, but have yet to be tested.

\section{Characteristics of the context of disclosure}

WGS is presently ordered for diagnostic and treatment purpose - situations where emotions are often high - making it hard for patients to attend to primary findings, much less IFs [37]. Physicians considering disclosure of IFs to patients will undoubtedly weigh their importance against the immediate needs of the situation and it is possible that disclosure of IFs that warrant action but are not immediately life-threatening will be delayed until immediate needs have been addressed. For example, disclosure of increased susceptibility to hypercholesterolemia might be delayed until cancer treatments have been completed. Moreover, clinicians are likely to omit disclosing IFs they judge to have questionable clinical utility altogether, such as variants of unknown significance with modest evidence of pathogenicity, or genetic markers indicating increases to disease risk too minor to affect clinical recommendations for prevention or treatment. As a consequence, where WGS IFs are disclosed may be different from where primary WGS findings are disclosed.

While WGS is traditionally considered a clinical tool, options are emerging in the consumer marketplace for both WGS itself and the interpretation of WGS results [49]. Situations may emerge where WGS was performed in a clinic for a specific diagnostic or treatment purpose, but where individuals take ownership and have their genomes interpreted through other means, raising oft-cited concerns for companies and their use of microchip arrays. Indeed, microarraybased genetic testing conducted in the marketplace has been criticized, in part due to concerns that companies are not rigorously confirming the associations between genetic markers and disease risk [50], an issue that is far more critical with respect to WGS. Naive interpreters of WGS information may assume that disease-causing variants listed in publicly accessible databases such as the Human Gene Mutation Database and dbSNP are accurate, rather than heavily 'contaminated' with exaggerated information [51]. It is beyond the scope of this piece to address the opportunities and challenges posed by the use of consumer genetics to provide and interpret WGS information. At present, ensuring the clinical validity of WGS IFs is still contingent upon the expertise of clinicians who manually distinguish meaningful genetic variants from those with no real association with disease [51]. The potential for people to receive and respond to inaccurate indications of disease risk is real, particularly in settings that attempt to automate the identification and categorization of sequencing variants.

Settings also play pivotal roles in enabling health behavior change by addressing outcomespecific needs. The impact of risk assessment programs on all types on health behaviors tends to be stronger when provided in healthcare settings than in workplace or community settings, arguably because the latter are not as well equipped or trained for facilitating lifestyle changes [52]. Most risk assessment interventions fall short by assuming that providing risk information alone can motivate change, ignoring the particular set of psychosocial constructs specific to any given health behavior that are more important determinants of changes, such as perceived barriers, behavioral capabilities and self-efficacy [53]. Initial analyses of the kinds of health behavior changes made following disclosure of incidental information in the aforementioned REVEAL Study suggest that they have low psychosocial barriers to change, such as adding over-the-counter supplements [6]. Achieving the kinds of health behavior changes that will substantially reduce disease risks for most complex conditions, such as increasing the frequency of moderate-intensity aerobic activities, eating more fruits and vegetables or stopping smoking, likely requires not only a motivated individual, but also vigorous engagement by health educators trained to increase behavioral capacity and self-efficacy. Certainly, popular and successful programs such as WeightWatchers ${ }^{\circledR}$ are common and the landscape of direct-to-consumer (DTC) genomic services continues to evolve. Whether genomic service providers go beyond simply communicating risk information to proactively facilitating health behavior change is likely to affect whether WGS IFs spur health behavior changes or not. 
It will also be crucial to monitor how market and clinical institutions interact. The rise of DTC genetic testing has raised concerns that consumers will use primary care physicians to help them interpret and respond to DTC test results, potentially requesting unnecessary follow-up services [54]. Moreover, great potential exists for individuals to be informed about health threats when they seek WGS simply for entertainment purposes, such as learning more about geographic ancestry. Consumers who seek the assistance of physicians to interpret and respond to DTC test or sequencing results may be disappointed or even misled, however. Healthcare professionals of all types tend to have poor understandings of genetics [55,56] and the same potential exists as for consumer services for physicians to blindly assume that benign variants are pathogenic based on exaggerated information in publicly available databases used to interpret WGS information.

Another contextual factor that is likely to affect whether or not individuals use WGS IFs to change health behaviors involves the question of whether patients have opted to receive them. While all IFs are likely to generate some level of surprise, whether or not individuals were provided the opportunity to decide whether or not they would receive IFs may affect whether they react positively or negatively to the information [57]. Extreme examples of how lack of choice can change perspectives towards information are the lawsuits over the storage and use of blood spots from newborn screening for research in Texas and Minnesota, where the omission of an informed consent step served as the crux of the grievances [58]. As one of the plaintiffs stated, "If they'd asked me if I would consent ... I would have probably said yes" [59]. While clinical analysis of voluntarily provided WGS samples represents a very different context than research on newborn blood samples provided through a compulsory program, it still demonstrates how giving individuals autonomy can change their attitudes towards events. Situations where participants are not given choices, particularly where they are emotionally charged, can cause them to shy away from information in some situations [60] or to respond in exactly the opposite way to that which was intended $[38,61]$. At the very least, providing individuals choices of whether or not they will be informed about IFs is likely to select for individuals with greater motivation to act on IF information. A plethora of studies of health behavior change, based on genetic information or otherwise, have found stronger effects among those who actively self-referred to the intervention compared with those who passively responded to offers to participate [62-64].

\section{Characteristics of patients}

We have already discussed important psychosocial determinants of health behaviors that WGS IFs may have the power to alter, particularly disease susceptibility and control perceptions, and personal autonomy. Other determinants that may be particularly important to consider are addressed here, namely personal and family histories of disease, patient emotional states and interpersonal relationships.

Personal and family histories of disease of individuals have strong associations with health behaviors and responses to genetic risk assessments $[65,66]$ and are likely to have a strong effect on how individuals respond to WGS IFs. Most of the concerns about IFs involve the potential for false-positives to unnecessarily provoke screening and follow-up procedures, but the reverse situation can also be true: IFs may help explain heretofore unexplained phenotypes and inform prevention and treatment strategies. In fact, incorporating these histories into choices regarding what to disclose is strongly recommended as a way to minimize the number of false-positives generated [67]. By providing an explanation for a personal or family history of disease, IF disclosure may be particularly effective at motivating behavior change.

Emotional states of patients are also likely to help determine how individuals respond to WGS IFs. Consistently, studies of genetic susceptibility testing have shown that individuals cope well with its results, even indications of increased risk [68]. However, evidence also shows that short-term increases in distress can occur [69]. Notably, minor increases in distress can spur health behavior change, but major distress can sometimes inhibit the ability of people to attend to information and in some cases even result in maladaptive responses [37,70]. It is likely that the original reasons for sequencing has already created an emotional situation and physicians will need to be careful that further disclosure of IFs does not push individuals into responding in ways that can be detrimental to their health.

Lastly, the familial implications of genetic information mean practitioners who disclose IFs need to be sensitive to their potential impact on the relatives of patients in addition to the patients themselves. WGS IFs resulting from germline mutations have direct implications for blood relatives and the disclosure of IFs in any given person 
has the potential to cascade into disclosure to family units. Clinicians should at least consider that IF information may or should be shared with a patient's relatives, depending on the nature of the IFs and the strength of familial relationships. In situations where patients want to or should communicate IFs with relatives, clinicians have an opportunity to suggest ways of doing so that maximize adaptive responses - behavioral and otherwise - and protect the rights to privacy and confidentiality of family members, while minimizing the risks of disrupting relationships.

\section{Looking ahead}

Our understanding of genomics has vast room for improvement. We can only explain a small proportion of the presumed genetic variance for most conditions [71] and our knowledge of how genes interact with one another and other factors, particularly gene-environment interactions, is poor. Using present genetic information to inform everyday choices such as meal preparation and how to exercise or choose working and living environments may be premature, even if services to do that currently exist. It may be decades before interactions between genes, behavior and environment are understood well enough to provide substantial utility to warrant individualized recommendations based on genomic profiles. Furthermore, behavior change interventions that take advantage of some of the more unique aspects of genetic risk information are in their infancy. Genetic information provides insight into specific biological barriers to lifestyle modification and could enrich personalized prevention strategies by identifying smokers who may be particularly sensitive to nicotine withdrawal, for instance [5,72]. These and other approaches are theoretical at present and not specific to the disclosure of incidental information. Nevertheless, given the relentless pace of genetic discoveries, it is likely that disease mechanisms - and corresponding prevention strategies - will be elucidated in the future. We remain optimistic that the issue is not whether such understandings will evolve, but when; and when it does, the ability of WGS IFs to inform health behaviors to decrease disease risk will improve markedly. In fact, the utility of disclosing WGS IFs will increase simply as our understanding of disease prevention and treatment improves. Genetic factors are thought to account for a small proportion of disease risk for most common diseases and an improved understanding of socio-behavioral risk factor reduction may be contributing to encouraging reductions in the incidence of diseases such as cancer in the USA [73]. If disclosure of WGS IFs represents a 'teachable moment' for clinicians to capitalize on, we might expect health behavior responses to improve in the future simply due to more efficacious prevention and treatment strategies.

Also worth noting here is that the psychological mechanisms we have addressed in this piece are only partially based on rational, planned models of intervention. Genetic susceptibility testing for AD conducted in the REVEAL Study and presented throughout this perspective piece has been one of few studies to show that genetic risk information - incidental or otherwise - can motivate heath behavior changes [5]. Genetic testing for hereditary breast cancer, colorectal cancer and melanoma syndromes appears to motivate at-risk individuals to adhere to screening recommendations [74,75], but the overwhelming majority of studies have shown no impact of genetic risk information for common diseases on lifestyle behaviors such as diet or exercise $[5,9,76]$. Interestingly, findings in the REVEAL Study were observed even though proven prevention strategies for AD are lacking [77]. While contextual differences (e.g., the emotional nature of $\mathrm{AD}$ ), methodological limitations (e.g., selfreported outcomes or enrollment primarily of first-degree relatives of AD patients) or participant misunderstandings might explain discrepancies between REVEAL Study findings and findings from the field at large; we also suggest that that behavior change in the REVEAL Study might have been observed precisely because AD lacks well-known prevention strategies. Health behaviors that contribute to heart disease or diabetes risk are well-understood, for example, and participants enrolling in genetic risk assessment trials involving those conditions likely knew what to do to reduce their risk before the intervention was conducted. By contrast, genetic testing for AD risk may motivate individuals to seek information on and adopt behaviors to reduce their AD risk that are not well known or proven, but might have some effect. Alternatively, motivation to change behaviors may be stronger in the context of AD prevention than for other diseases because individuals believe that they would have to modify behaviors sooner and more vigorously to achieve results. Whatever the reasons, the evidence suggesting genetic susceptibility testing for $\mathrm{AD}$ risk can motivate behavior changes when testing for more modifiable conditions cannot highlight how behavioral responses to genetic information can be counterintuitive and the field should not dismiss the potential health 
behavior benefits of disclosing WGS IFs until more research has been conducted.

Similarly, the field needs to be sensitive to the potential for IF disclosure to provoke health behaviors that may be counter-productive. We have generally focused here on whether or not health behavior changes might ensue from disclosing incidental information, not whether or not such changes are warranted or even beneficial. Initial fears that genetic information about modifiable conditions might be interpreted deterministically and cause individuals to increase maladaptive behaviors have not been borne out $[10,30]$; however, genetic testing has been shown to motivate some individuals to adopt behaviors that are not of confirmed beneficence, such as taking nutritional supplements [78,79]. Given that WGS likely attracts those with favorable attitudes towards science and technology, early users of WGS may be especially willing to try unproven prevention strategies.

Lastly, it is worth noting that the whole issue of IFs from WGS may decrease over time. The definition of IFs used in this piece presumes a goal to sequencing, such as the diagnosis of disease or the optimization of treatment. Many have even presumed that WGS of individuals, perhaps even at birth, will be commonplace and used as a kind of universal screening tool [80]. Even if WGS is limited to providing health information, however, WGS can provide information about traits that do not directly affect health, but potentially impact health behaviors. Consumer genetic testing already provides information about traits such as earwax type and eye patterns. Could WGS IFs about traits such as height motivate children to choose playing basketball over gymnastics? One of the most popular uses of consumer genetic testing, the disclosure of geographic ancestry, can have powerful effects on how individuals think about themselves and how others think about the person profiled. Could the disclosure of ancestry motivate individuals to adopt more ethnic diets? Almost certainly, this is the type of incidental information that would not be 'imposed' upon individuals. Does volitionally seeking the information select for people who are willing to have their identities 'primed'? These are just a few of the more complicated ways in which WGS information may cause people to change health behaviors.

\section{Conclusion}

The possibility exists for WGS IFs to influence health behaviors more than intentionally sought genetic risk information, but changes are likely to occur in only particular contexts when information is communicated in particular ways, and the changes that ensue may not be either warranted or desirable. Important to keep in mind, also, is that most of the arguments asserted in this piece are based on a very limited body of empirical evidence. Substantial efforts are being made to gather empirical evidence of the impact of disclosing incidental information identified during biobanking and other types of biological work. Concurrent efforts are also being made to understand how people understand and respond to WGS not just in the diagnostic context, but as a screening tool in primary care. Empirical data of the effects of disclosing incidental information from WGS is forthcoming. In the meantime, physicians and policy-makers would be best served to reserve judgment on the beneficial or detrimental impact of disclosing WGS IFs on health behaviors are clearer.

\section{Future perspective}

Incidental information disclosure will be increasingly common as more and more physicians incorporate WGS into their practices, and it is likely to affect many patients' health behaviors. The psychological processes behind changes may differ from those typically exploited in lifestyle interventions, however, and changes may be neither warranted nor beneficial. The likelihood that changes ensue will depend not only on what is disclosed and the effectiveness of prevention and treatment strategies, but also on whether the information is communicated parsimoniously and in ways that align with existing attitudes and beliefs. Furthermore, contextual factors will be important, including whether patients were forewarned about receiving IFs and whether disclosure is accompanied by services to facilitate understandings and behavior changes. Finally, whether individuals adopt behavior changes will be affected by individual-level factors such as patients' attitudes towards genetic risk information and their abilities to process it. Practitioners should be cautiously optimistic about the ability of incidental information from WGS to motivate positive health behavior changes.

Financial \& competing interests disclosure

This work is supported by NIH grants HG006993, HG006500, HG002213 and HG005092. The authors have no other relevant affiliations or financial involvement with any organization or entity with a financial interest in or financial conflict with the subject matter or materials discussed in the manuscript apart from those disclosed.

No writing assistance was utilized in the production of this manuscript. 


\section{Executive summary}

\section{Health behaviors \& incidental findings}

- Whole-genome sequencing (WGS) can identify thousands of genetic variants of variable utility that may be incidental to the original purposes of sequencing.

- Preliminary analyses of the behavioral impact of disclosing incidental cardiovascular disease associations during a genetic risk assessment for Alzheimer's disease suggest that it motivates individuals to change multiple types of health behaviors.

- Although genetic risk assessments for common diseases have shown little ability to motivate behavior changes, disclosure of incidental findings (IFs) may be effective since it elicits a different kind of psychological response.

\section{Characteristics of the information \& how it is communicated}

- The ability of WGS IF disclosure to motivate health behavior change may be dependent not only on the kind, but also on the quantity, of information disclosed.

- The behavioral impact of WGS IFs might be augmented if they are communicated in ways that align with patients' identities.

\section{Characteristics of the context of disclosure}

- For WGS conducted with a purpose, consideration of IFs may be delayed by the need to address primary findings.

- A combination of clinical and marketplace settings may be involved in interpreting WGS information, affecting what is identified as clinically significant and what kind of services are offered to support health behavior changes.

- Forewarning individuals that they may receive IFs may make them more receptive to the information and prime them towards making behavior changes.

\section{Characteristics of patients}

- Responses to IF disclosure may be additionally affected by patients' personal and family histories of disease, emotional states and interpersonal relationships.

\section{Looking ahead}

- An improving understanding of gene-behavior and gene-environment interactions, and disease prevention more generally is likely to increase the clinical utility of WGS information, and thus the utility of IF disclosure.

- Physicians and policymakers need to be sensitive to the ways WGS may affect health behaviors through many different psychological mechanisms.

\section{References}

Papers of special note have been highlighted as:

- of interest

"I" of considerable interest

1 Lander ES. Initial impact of the sequencing of the human genome. Nature 470 (7333), 187-197 (2011).

2 Gilissen C, Hoischen A, Brunner H, Veltman J. Unlocking Mendelian disease using exome sequencing. Genome Biol. 12(9), 228 (2011).

3 Wolf SM, Lawrenz FP, Nelson CA et al. Managing incidental findings in human subjects research: analysis and recommendations. J. Law Med. Ethics 36(2), 219-248 (2008).

4 Meacham MC, Starks H, Burke W, Edwards $\mathrm{K}$. Researcher perspectives on disclosure of incidental findings in genetic research. J. Empir. Res. Hum. Res. Ethics 5(3), 31-41 (2010).

5 McBride CM, Koehly LM, Sanderson SC, Kaphingst KA. The behavioral response to personalized genetic information: will genetic risk profiles motivate individuals and families to choose more healthful behaviors? Annu. Rev. Public Health 31(1), 89-103 (2010).

"Excellent synthesis of the literature on whether genetic information can motivate health behavior changes.
6 Chao S, Roberts JS, Marteau TM, Silliman R, Cupples LA, Green RC. Health behavior changes after genetic risk assessment for Alzheimer disease: the REVEAL study. Alzheimer Dis. Assoc. Disord. 22(1), 94-97 (2008).

7 Taylor DH, Cook-Deegan RM, Hiraki S, Roberts JS, Blazer DG, Green RC. Genetic testing for Alzheimer's and long-term care insurance. Health Aff. 29(1), 102-108 (2010).

8 de Viron S, van der Heyden J, Ambrosino E, Arbyn M, Brand A, Van Oyen H. Impact of genetic notification on smoking cessation: systematic review and pooled-analysis. PLoS ONE 7(7), e40230 (2012).

9 Bloss CS, Schork NJ, Topol EJ. Effect of direct-to-consumer genome wide profiling to assess disease risk. N. Engl. J. Med. 364(6), 524-534 (2011).

10 Marteau TM, French DP, Griffin SJ et al. Effects of communicating DNA-based disease risk estimates on risk-reducing behaviours. Cochrane Database Syst. Rev. 10, CD007275 (2010).

11 Christensen KD, Roberts JS, Uhlmann WR et al. How does pleiotropic information affect health behavior changes? Initial results from the REVEAL study, a randomized trial of genetic testing for Alzheimer's disease risk. Presented at: 2010 ACMG Annual Clinical
Genetics Meeting. Albuquerque, NM, USA, 24-28 March 2010.

12 Christensen KD, Roberts JS, Uhlmann WR et al. The psychological impact of learning about APOE-cardiovascular disease associations during genetic risk assessment for Alzheimer's disease: findings from the REVEAL study. Alzheimers Dement. 6(4 Suppl. 1), S96-S96 (2010).

13 Green RC, Berg JS, Berry GT et al. Exploring concordance and discordance for return of incidental findings from clinical sequencing. Genet. Med. 14(4), 405-410 (2012).

"- Highlights the lack of consensus among physicians regarding what kinds of incidental findings should be disclosed to patients.

14 Becker MH, Janz NK. Behavioral science perspectives on health hazard/health risk appraisal. Health Serv. Res. 22(4), 537-551 (1987).

15 Rosenstock IM. Historical origins of the health belief model. Health Educ. Monogr. 2(4), 328-335 (1974).

16 Matzger H, Kaskutas LA, Weisner C. Reasons for drinking less and their relationship to sustained remission from problem drinking. Addiction 100(11), 1637-1646 (2005). 
17 West R, Sohal T. 'Catastrophic' pathways to smoking cessation: findings from national survey. BMJ 332(7539), 458-460 (2006).

18 Ferguson SG, Shiffman S, Gitchell JG, Sembower MA, West R. Unplanned quit attempts - results from a US sample of smokers and ex-smokers. Nicotine Tob. Res. 11(7), 827-832 (2009).

19 Resnicow K, Page SE. Embracing chaos and complexity: a quantum change for public health. Am. J. Public Health 98(8), 1382-1389 (2008).

- Excellently thought out piece that suggests that health educators should help patients reach 'mini-epiphanies' about health behavior change.

20 Fabsitz RR, McGuire A, Sharp RR et al. Ethical and practical guidelines for reporting genetic research results to study participants. Circ. Cardiovasc. Genet. 3(6), 574-580 (2010).

21 Downing NR, Williams JK, Daack-Hirsch S, Driessnack M, Simon CM. Genetics specialists' perspectives on disclosure of genomic incidental findings in the clinical setting. Patient Educ. Couns. 90(1), 133-138 (2013).

22 Wright C, Burton H, Hall A et al. Next Steps in the Sequence. The Implications of Whole Genome Sequencing for Health in the UK. PHG Foundation, Cambridge, UK (2011).

23 McGuire AL, Lupski JR. Personal genome research: what should the participant be told? Trends Genet. 26(5), 199-201 (2010).

24 Berg JS, Khoury MJ, Evans JP. Deploying whole genome sequencing in clinical practice and public health: meeting the challenge one bin at a time. Genet. Med. 13(6), 499-504 (2011).

25 Institute of Medicine. Integrating Large-Scale Genomic Information into Clinical Practice: Workshop Summary. The National Academies Press, Washington, DC, USA (2012).

26 Janz NK, Becker MH. The health belief model: a decade later. Health Educ. Q. 11(1), 1-47 (1984).

27 Linnenbringer E, Roberts JS, Hiraki S, Cupples LA, Green RC. 'I know what you told me, but this is what I think:' perceived risk of Alzheimer disease among individuals who accurately recall their genetics-based risk estimate. Genet. Med. 12(4), 219-227 (2010).

28 Audrain-Mcgovern J, Hughes C, Patterson F. Effecting behavior change: awareness of family history. Am. J. Prev. Med. 24(2), 183-189 (2003).

29 Heshka JT, Palleschi C, Howley H, Wilson B, Wells PS. A systematic review of perceived risks, psychological and behavioral impacts of genetic testing. Genet. Med. 10(1), 19-32 (2008).
30 Collins RE, Wright AJ, Marteau TM. Impact of communicating personalized genetic risk information on perceived control over the risk: a systematic review. Genet. Med. 13(4), 273-277 (2011).

31 Biesecker LG. Opportunities and challenges for the integration of massively parallel genomic sequencing into clinical practice: lessons from the ClinSeq project. Genet. Med. 14(4), 393-398 (2012).

- Informative overview of the experiences of one group providing clinical whole-genome sequencing, including the challenges of deciding what to disclose to patients.

32 Murphy J, Scott J, Kaufman D, Geller G, Leroy L, Hudson K. Public expectations for return of results from large-cohort genetic research. Am. J. Bioeth. 8(11), 36-43 (2008).

33 Harris ED, Ziniel SI, Amatruda JG et al. The beliefs, motivations, and expectations of parents who have enrolled their children in a genetic biorepository. Genet. Med. 14(3), 330-337 (2012).

34 Zikmund-Fisher BJ, Angott A, Ubel P. The benefits of discussing adjuvant therapies one at a time instead of all at once. Breast Cancer Res. Treat. 129(1), 79-87 (2011).

35 Zikmund-Fisher BJ, Fagerlin A, Ubel PA. A demonstration of 'less can be more' in risk graphics. Med. Decis. Making 30(6), 661-671 (2010).

36 Ruffin MT, Nease DE Jr, Sen A et al. Effect of preventive messages tailored to family history on health behaviors: the family healthware impact trial. Ann. Fam. Med. 9(1), 3-11 (2011).

37 Petty RE, Cacioppo JT. The elaboration likelihood model of persuasion. In: Advances in Experimental Social Psychology. Berkowitz L (Ed.). Academic Press, NY, USA, 124-205 (1986).

38 Ringold D. Boomerang effects in response to public health interventions: some unintended consequences in the alcoholic beverage market. J. Consumer Policy 25(1), 27-63 (2002).

39 Brehm JA. Theory of Psychological Reactance. John Wiley \& Sons, CA, USA (1966).

40 Marteau TM, Senior V, Humphries SE et al. Psychological impact of genetic testing for familial hypercholesterolemia within a previously aware population: a randomized controlled trial. Am. J. Med. Genet. A 128A(3), 285-293 (2004).

41 Richards M. Families, kinship and genetics. In: The Troubled Helix: Social and Psychological Implications of the New Human Genetics. Marteau T, Richards M (Eds). Cambridge University Press, Cambridge, NY, USA, 249-273 (1996).
42 Nelkin D, Lindee MS. The DNA Mystique: the Gene as a Cultural Icon. University of Michigan, MI, USA (2004).

43 Roberts JS. Surveying customer responses to personal genetic services. Presented at: The American Society of Human Genetics 62nd Annual Meeting. San Francisco, CA, USA, 6-10 November 2012.

44 Resnicow K, McMaster F. Motivational Interviewing: moving from why to how with autonomy support. Int. J. Behav. Nutr. Phys. Act. 9(1), 19 (2012).

45 Shiloh S. Illness representations, selfregulation, and genetic counseling: a theoretical review. J. Genet. Couns. 15(5), 325-337 (2006).

46 Baumeister RF. The self. In: The Handbook of Social Psychology. Gilbert DT, Fiske ST, Lindzey G (Eds). McGraw-Hill, NY, USA. 680-740 (1998).

47 Steele CM. The psychology of selfaffirmation: sustaining the integrity of the self. In: Advances in Experimental Social Psychology. Berkowitz L (Ed.). Academic Press, CA, USA, 261-302 (1988).

48 Etchegary H, Perrier C. Information processing in the context of genetic risk: implications for genetic-risk communication. J. Genet. Couns. 16(4), 419-432 (2007).

49 Rochman B. Test your DNA for diseases - no doctor required. Time, 23rd October (2012).

50 Janssens AC, Gwinn M, Bradley LA, Oostra BA, van Duijn CM, Khoury MJ. A critical appraisal of the scientific basis of commercial genomic profiles used to assess health risks and personalize health interventions. Am. J. Hum. Genet. 82(3), 593-599 (2008).

51 Berg JS, Adams M, Nassar N et al. An informatics approach to analyzing the incidentalome. Genet. Med. 15(1), 36-44 (2013).

52 Bankhead CR, Brett J, Bukach C et al. The impact of screening on future healthpromoting behaviours and health beliefs: a systematic review. Health Technol. Assess. 7(42), 1-92 (2003).

53 Strecher VJ, Kreuter MW. The psychosocial and behavioral impact of health risk appraisals. In: Psychosocial Effects of Screening for Disease Prevention and Detection. Croyle RT (Ed.). Oxford University Press, NY, USA 126-143 (1995).

54 McGuire AL, Burke W. An unwelcome side effect of direct-to-consumer personal genome testing: raiding the medical commons. JAMA 300(22), 2669-2671 (2008).

55 Secretary's Advisory Committee on Genetics, Health and Society. Genetics Education and Training. Department of Health \& Human Services, Washington, DC, USA (2011). 
56 Suther S, Goodson P. Barriers to the provision of genetic services by primary care physicians: a systematic review of the literature. Genet. Med. 5(2), 70-76 (2003).

57 Archibald AD, Hickerton CL, Jaques AM, Wake S, Cohen J, Metcalfe SA. 'It's about having the choice': stakeholder perceptions of population-based genetic carrier screening for fragile X syndrome. Am. J. Med. Genet. A 161(1), 48-58 (2013).

- Recent study highlighting the importance of giving patients choices when considering genetic screening.

58 Tarini BA. Storage and use of residual newborn screening blood spots: a public policy emergency. Genet. Med. 13(7), 619-620 (2011).

59 Roser MA. State sued over babies' blood. Austin American-Statesman, 13th March (2009).

60 Sangha KK, Dircks A, Langlois S. Assessment of the effectiveness of genetic counseling by telephone compared with a clinic visit. J. Genet. Couns. 12(2), 171-184 (2003).

61 Witte K, Allen M. A meta-analysis of fear appeals: implications for effective public health campaigns. Health Educ. Behav. 27(5), 591-615 (2000).

62 McBride CM, Curry SJ, Grothaus LC, Rosner D, Louie D, Wagner EH. Use of self-help materials and smoking cessation among proactively recruited and volunteer intervention participants. Am. J. Health Promot. 12(5), 321-324 (1998).

63 Tzelepis F, Paul CL, Walsh RA, McElduff P, Knight J. Proactive telephone counseling for smoking cessation: meta-analyses by recruitment channel and methodological quality. J. Natl Cancer Inst. 103(12), 922-941 (2011).
64 Christensen KD, Roberts JS, Zikmund-Fisher BJ, Kardia SL, Mcbride CM, Green RC. Self-referral to genetic susceptibility testing for Alzheimer's disease: implications for uptake and responses to results. Presented at: The 2013 ACMG Annual Clinical Genetics Meeting. Phoenix, AZ, USA, 19-23 March 2013.

65 Manne S, Fasanella N, Connors J, Floyd B, Wang H, Lessin S. Sun protection and skin surveillance practices among relatives of patients with malignant melanoma: prevalence and predictors. Prev. Med. 39(1), 36-47 (2004).

66 Berwick M, Begg CB, Fine JA, Roush GC, Barnhill RL. Screening for cutaneous melanoma by skin self-examination. J. Natl Cancer Inst. 88(1), 17-23 (1996).

67 Kohane IS, Hsing M, Kong SW. Taxonomizing, sizing, and overcoming the incidentalome. Genet. Med. 14(4), 399-404 (2012).

68 Rew L, Kaur M, McMillan A, Mackert M, Bonevac D. Systematic review of psychosocial benefits and harms of genetic testing. Issues Ment. Health Nurs. 31(10), 631-645 (2010).

69 Green RC, Roberts JS, Cupples LA et al. Disclosure of $A P O E$ genotype for risk of Alzheimer's disease. N. Engl. J. Med. 361(3), 245-254 (2009).

70 Witte K. Putting the fear back into fear appeals: the extended parallel process model. Commun. Monogr. 59(4), 329-349 (1992).

71 Eichler EE, Flint J, Gibson G et al. Missing heritability and strategies for finding the underlying causes of complex disease. Nat. Rev. Genet. 11(6), 446-450 (2010).

72 McBride CM, Bryan AD, Bray MS, Swan GE, Green ED. Health behavior change: can genomics improve behavioral adherence? Am. J. Public Health 102(3), 401-405 (2012).
- Presents innovative ideas for how genetic information might be better used to help patients improve health behaviors.

73 Colditz GA, Wei EK. Preventability of cancer: the relative contributions of biologic and social and physical environmental determinants of cancer mortality. Annu. Rev. Public Health 33(1), 137-156 (2012).

74 Beery TA, Williams JK. Risk reduction and health promotion behaviors following genetic testing for adult-onset disorders. Genet. Test. 11(2), 111-123 (2007).

75 Kasparian NA, Meiser B, Butow PN, Simpson JM, Mann GJ. Genetic testing for melanoma risk: a prospective cohort study of uptake and outcomes among Australian families. Genet. Med. 11(4), 265-278 (2009).

76 Grant RW, O’Brien KE, Waxler JL et al. Personalized genetic risk counseling to motivate diabetes prevention: a randomized trial. Diabetes Care 36(1), 13-19 (2013).

77 Morris JC. Dementia update 2005. Alzheimer Dis. Assoc. Disord. 19(2), 100-117 (2005).

78 Alamian A, Rouleau I, Simard J, Dorval M. Use of dietary supplements among women at high risk of Hereditary Breast and Ovarian Cancer (HBOC) tested for cancer susceptibility. Nutr. Cancer 54(2), 157-165 (2006).

79 Vernarelli JA, Roberts JS, Hiraki S, Chen CA, Cupples LA, Green RC. Effect of Alzheimer disease genetic risk disclosure on dietary supplement use. Am. J. Clin. Nutr. 91(5), 1402-1407 (2010).

80 The President's Council on Bioethics. The Changing Moral Focus of Newborn Screening: an Ethical Analysis by the President's Council on Bioethics. The President's Council on Bioethics, Washington, DC, USA (2008). 